Research Article

\title{
Numerical Well Test Analysis of Condensate Dropout Effects in Dual-Permeability Model of Naturally Fractured Gas Condensate Reservoirs: Case Studies in the South of Iran
}

\author{
Mohsen Safari-Beidokhti ${ }^{D},{ }^{1}$ Abdolnabi Hashemi ${ }^{D}{ }^{2}{ }^{2}$ Reza Abdollahi ${ }^{D},{ }^{1}$ \\ Hamed Hematpur $\mathbb{D}^{1},{ }^{1}$ and Hamid Esfandyari $\mathbb{C}^{3}$ \\ ${ }^{1}$ EOR Research Department, Research Institute of Petroleum Industry, Tehran, Iran \\ ${ }^{2}$ Department of Petroleum Engineering, Petroleum University of Technology, Ahvaz, Iran \\ ${ }^{3}$ Abadan Faculty of Petroleum Engineering, Petroleum University of Technology, Abadan, Iran \\ Correspondence should be addressed to Hamid Esfandyari; esfandyari_shirazu@yahoo.com
}

Received 1 April 2021; Revised 19 April 2021; Accepted 27 April 2021; Published 7 May 2021

Academic Editor: Mohammad Yazdi

Copyright (C) 2021 Mohsen Safari-Beidokhti et al. This is an open access article distributed under the Creative Commons Attribution License, which permits unrestricted use, distribution, and reproduction in any medium, provided the original work is properly cited.

\begin{abstract}
Naturally fractured reservoirs (NFR) represent an important percentage of worldwide hydrocarbon reserves and production. The performance of naturally fractured gas condensate reservoirs would be more complicated regarding both rock and fluid effects. In contrast to the dual-porosity model, dual-porosity/dual-permeability (dual-permeability) model is considered as a modified model, in which flow to the wellbore occurs through both matrix and fracture systems. Fluid flow in gas condensate reservoirs usually demonstrates intricate flow behavior when the flowing bottom-hole pressure falls below the dew point. Accordingly, different regions with different characteristics are formed within the reservoir. These regions can be recognized by pressure transient analysis. Consequently, distinguishing between reservoir effects and fluid effects is challenging in these specific reservoirs and needs numerical simulation. The main objective of this paper is to examine the effect of condensate banking on the pressure behavior of lean and rich gas condensate NFRs through a simulation approach. Subsequently, evaluation of early-time characteristics of the pressure transient data is provided through a single well compositional simulation model. Then, drawdown, buildup, and multirate tests are conducted to establish the condition in which the flowing bottom-hole pressure drops below the dew point causing retrograde condensation. The simulation results are confirmed through well test analysis in both Iranian naturally fractured rich and lean gas condensate fields. Interpretations of simulation analysis revealed that the richer gas is more prone to condensation. When the pressure drops below the dew point, the pressure derivative curves in the rich gas system encounter a more shift to the right, and the trough becomes more pronounced as compared to the lean one.
\end{abstract}

\section{Introduction}

1.1. Naturally Fractured Reservoirs. A substantial amount of worldwide oil and gas was produced by Naturally Fractured Reservoirs (NFR) [1-8]. The recovery factor in NFR varies widely (10 to over $60 \%$ ). On the one hand, fractures could play the role of the main path of fluid flow, especially in tight formations, and consequently improve the ultimate reservoir recovery [9]. On the other hand, fractures may have the adverse effect on reservoir productivity and cause earlier unwanted water production, erratic sweep patterns, and consequently low recovery factor [9-11]. This issue is more critical in naturally fracture water drive gas reservoirs. This water expansion in naturally fractured reservoirs, particularly with low matrix permeability, fills up the fractures, and the free gas will stop flowing. Thus, water would be the only fluid passing through the fractures, and early breakthrough happens [12]. Beaver River Field of Canada [13], Dengying gas reservoir in Weiyuan gas Field in China [14], and Aguarague Field in Argentina [15] with the gas recovery of 12,37 , and 34 percent, respectively, are 
examples of these kinds of reservoirs. Thus, the effect of fracture on ultimate reservoir recovery could be either positive or negative.

Well test data can offer crucial information about the reservoir properties. The existence of fractures introduces a layer of difficulty in interpreting the pressure response. By now, several idealizations have been suggested to analyze the NFR pressure behavior. The most common idealization is the dual-porosity model proposed by Barenblatt et al. (1960). This model was firstly applied in reservoir engineering by Warren and Root (1963) by introducing two additional parameters as follows [16].

Storativity ratio $(\omega)$ :

$$
\omega=\frac{\left(\varphi c_{t}\right)_{\text {fracture }}}{\left(\varphi c_{t}\right)_{\text {fracture }}+\left(\varphi c_{t}\right)_{\text {matrix }}} .
$$

Interporosity flow coefficient $(\lambda)$ :

$$
\lambda=\frac{\alpha k_{\text {matrix }} r_{w}^{2}}{k_{\text {fracture }}},
$$

in which $\alpha$ is defined as

$$
\alpha=\frac{4 n(n+2)}{L_{\text {matrix }}^{2}} .
$$

Figure 1 depicts different matrix system elements, $n=1$, 2, 3 for slab, cylinder, and cubic matrix blocks, respectively [17]. The dual-porosity model assumes the existence of the two media with large bulk porosity/relatively low permeability (matrix) and very low bulk porosity/relatively high permeability (fracture). In this model, fluid flow from the matrix to the fracture system, and subsequently, through the fracture to the wellbore, leads to hydrocarbon production. The fluid regime between the matrix and interconnected fracture is pseudosteady state flow [18-21].

The incorporation of the dual-porosity idealization and numerical modeling for large-scale fluid flow application was firstly introduced by Kazemi et al. (1976) [19]. It has been recognized as the standard for NFR modeling and well test interpretation $[5,9,18-29]$.

Figure 2 depicts the pressure transient behavior in the dual-porosity model. Figure 3 represents the different flow behaviors of such reservoirs on log-log pressure derivative response schematically $[16,21]$.

The dual-porosity dual-permeability is another idealization introduced to improve the previous dual-porosity model. This idealization was first suggested by Blaskovich et al. (1983) and Hill and Thomas (1985). Matrix blocks are connected in this model and participate in the overall fluid flow. In comparison to the dual-porosity model, which is suitable only for intensely fractured reservoirs, the dualporosity/permeability model can be applied for many reservoirs with different fracture degrees [31-36].

Figures 4 and 5 show a schematic of fluid flow in these two aforementioned models [37].

Overall, dual-porosity/dual-permeability reservoir includes two homogeneous layers. The cross flow between layers exists, and both can flow into the well. The pressure difference between layers determined the amount of interlayer cross flow. The parameters resulting from well test analysis define the mathematic model to describe this reservoir [38]:

Mobility ratio $(\kappa)$ :

$$
\kappa=\frac{k_{1} h_{1}}{k_{1} h_{1}+k_{2} h_{2}}=\frac{k_{1} h_{1}}{k h_{\mathrm{TOTAL}}} .
$$

Storativity ratio $(\omega)$ :

$$
\omega=\frac{\left(\varphi C_{t} h\right)_{1}}{\left(\varphi C_{t} h\right)_{1}+\left(\varphi C_{t} h\right)_{2}}=\frac{\left(\varphi C_{t} h\right)_{1}}{\left(\varphi C_{t} h\right)_{\text {Total }}} .
$$

Interlayer cross flow coefficient $(\lambda)$ :

$$
\lambda=\frac{r_{w}{ }^{2}}{k_{1} h_{1}+k_{2} h_{2}} \cdot \frac{2}{h_{1} / k_{z 1}+h_{2} / k_{z 2}} .
$$

At the early time, cross-flow does not occur, and the layers are produced independently. When the interlayer cross flow starts, a transition period is detected by an inflection in the pressure response and a valley in the derivative. After the transition, the reservoir acts as a homogeneous medium, with total $k h$ and storativity. When the mobility ratio is equal to one, the response of the dualporosity and dual-porosity/permeability is the same. In addition, the response tends to a homogeneous reservoir when the mobility ratio decreases, as shown in Figure 6.

The different flow behavior, which can be observed in the $\log -\log$ pressure derivative, is the same as that in Figure 3. The only difference is that, in all cases, the matrix can also produce into the well [21]. Many researches have been conducted on naturally fractured reservoirs applying the dual-porosity and dual-permeability model [36, 38-51].

1.2. Gas Condensate Reservoirs and Pressure Transient Analysis. A gas condensate is a naturally occurring hydrocarbon mixture found between the cricondentherm and critical reservoir temperature [52-55]. It can be categorized into rich and lean gas condensate reservoirs. Below the dew point, rich and lean gas condensate generates 100 and more than $150 \mathrm{STB} / \mathrm{MMSCF}$ of liquid, respectively [56]. Due to the complex phase and fluid flow behavior of these reservoirs, their evaluation becomes a challenging issue. With condensate accumulation around the well, the effective permeability is reduced substantially [38, 57-68].

The first investigation on condensate blockage was directed by Muskat (1949) [69]. O’Dell and Miller (1967) suggested a pseudopressure equation to analyze this phenomenon. This equation is limited to reservoirs over the dew point pressure and when the radius of condensate banking is not significant. In 1973, Fussel developed the compositional model, which was applicable to analysis gas condensate reservoirs behavior below the dew point pressure [70]. Later, Jones, and Raghavan (1988) used buildup and drawdown pressure tests to study the gas condensate reservoirs [71]. The concept three-flow region in gas condensate reservoirs was proposed by Fevang and Whitson (1996) and Penuela 

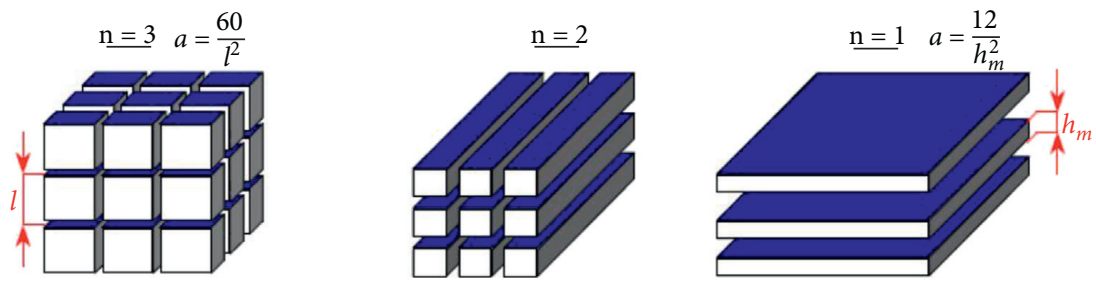

FIgURE 1: Three different matrix block geometries in the dual-porosity model [17].

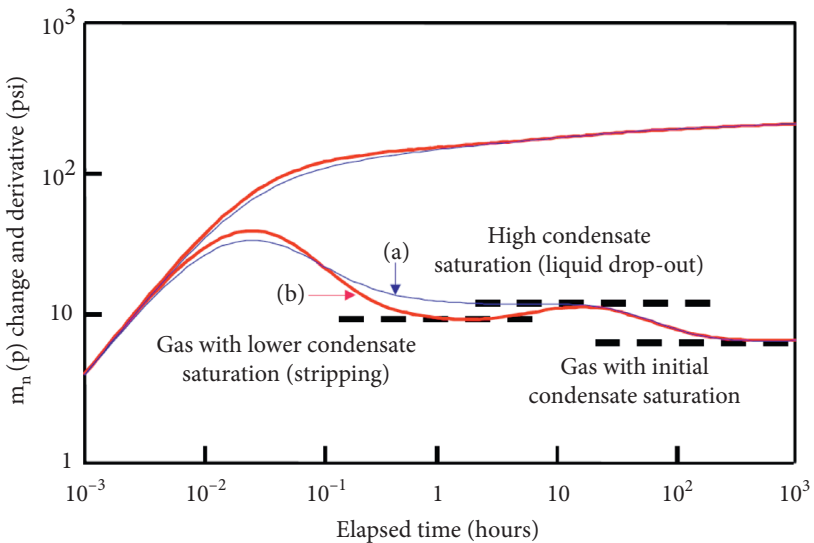

Figure 2: Schematic of pressure and derivative of composite behaviors: (a) two- and (b) three-region composite

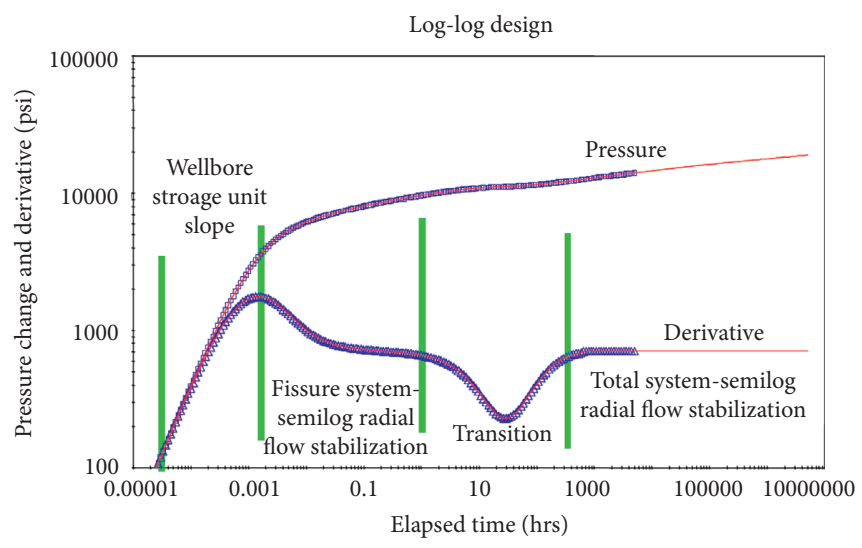

Figure 3: Pressure and derivative log-log curve in dual-porosity reservoirs.

and Civan (2000) [59, 72]. Properties of these regions can be summarized as follows:

Region (1): this is the farthest region around the well with pressure over the dew point. The system contains a single gas-phase including the initial liquid saturation.

Region (2): this region is near the first region toward the well. It is generated with pressure reduction below the dew point, and where the liquid saturation increases rapidly. It should be noted that, in this region, the liquid phase is immobile $(\mathrm{SL}<\mathrm{SLC})$.

Region (3): this region is the nearest region around the well. The liquid saturation is higher than the critical

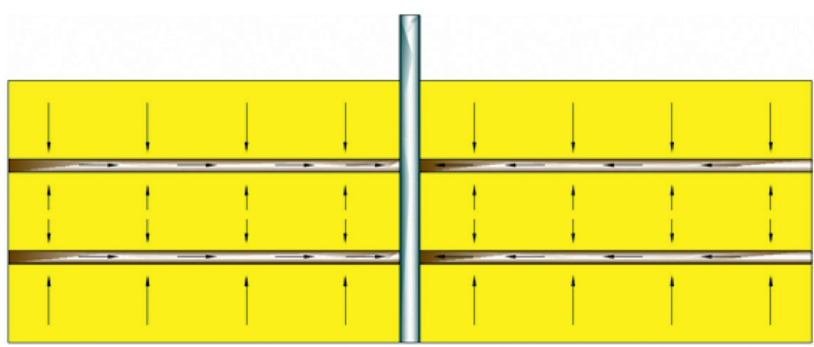

FIGURE 4: Dual-porosity idealization of naturally fractured reservoirs [36].

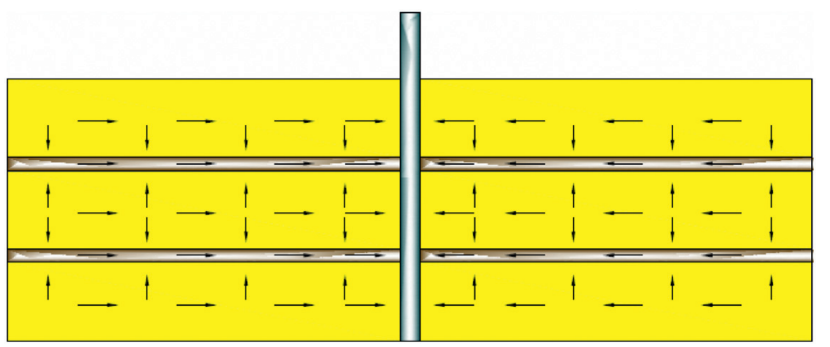

FIGURE 5: Dual-porosity/dual-permeability idealization of naturally fractured reservoirs [36].

saturation of condensate, so, gas and oil phases are mobile.

In some references, the existence of another region in the vicinity of wells was reported. This fourth region was firstly reported by Gringarten et al. (2000) [30].

Three-region composite is the most frequently used model in the gas condensate reservoir evaluation [42, 52, 56, 58-63].

One of the approved methods in investigating the gas condensate reservoir behavior is well-test analysis (pressure transient tests). Figure 7 shows the regions around the wellbore by applying a single-phase pseudopressure function for gas condensate reservoir.

Due to the high conductivity of fractures, condensate flow in fractures is simpler, and consequently, condensate saturation near the wellbore can be higher with respect to other regions in reservoirs. In opposition, the residual condensate saturation in the matrix is relatively large; hence, it could remain immobile for quite sometimes.

In gas condensate NFRs, these regions are usually formed in the fracture system because of the high fracture mobility and minor change in matrix gas saturation. Figure 8 illustrates the profile of gas saturation in naturally fracture reservoirs [37]. 


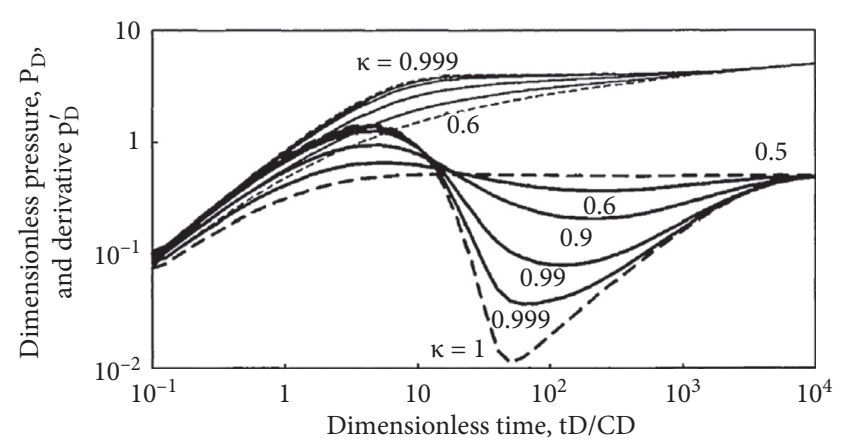

Figure 6: Pressure and derivative log-log curve in dual-porosity/ dual-permeability reservoir. The two dashed curves correspond to the homogeneous reservoir responses $(\kappa=0.5)$ and dual-porosity response $(\kappa=1)$ [21].

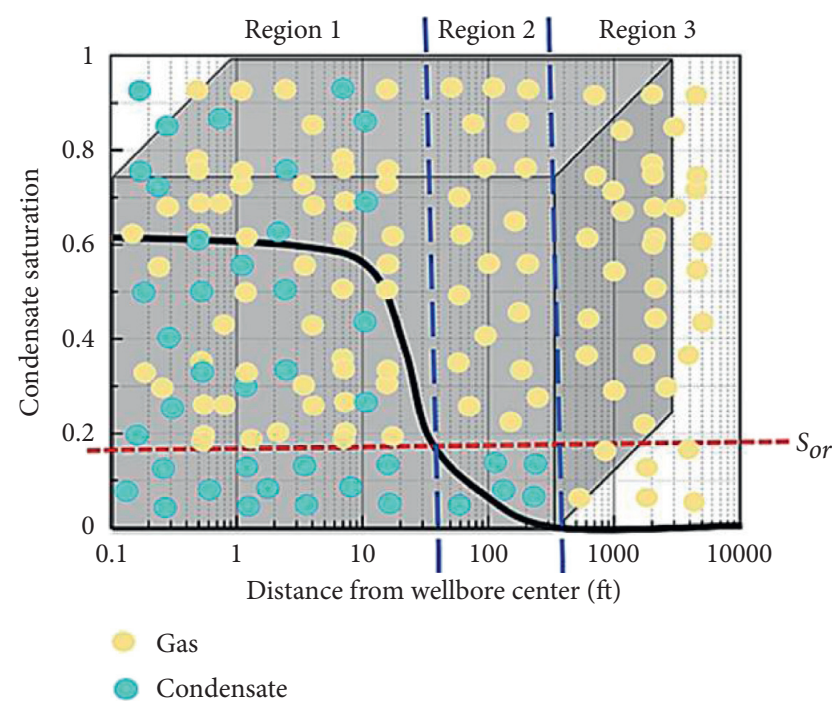

FIgURE 7: Different regions of condensate dropout.

Interaction of competing viscous, capillary, and inertial forces as the pressure change during reservoir life can affect the well deliverability of gas condensate reservoirs. The physical processes that reduce productivity are condensate banking, and inertial effect, which leads to the reduction of $k_{r g}$ as the velocity increases. Conversely, positive coupling or velocity stripping effect (capillary number effect) results in the increase of gas relative permeability and to some extent that of liquid, as velocity increases and/or IFT decreases. The overall balance of these forces specifies the well deliverability [30].

\section{Approach}

Since there is not any analytical composite model for gas condensate NFRs, a numerical compositional model is a suitable choice to assess the pressure behavior in these types of reservoirs.

In the current study, the effect of condensate banking on the pressure behavior of lean and rich gas condensate NFRs is investigated through a simulation approach. The necessary simulation data (fluid and rock properties) was acquired from a real gas condensate field. Multirate tests (drawdown and buildup) were conducted to create a condition in which the flowing bottomhole pressure went below the dew point, and consequently, the condensate was formed. In the next step, the results of the numerical model were analyzed by standard well tests analysis to derive the results.

2.1. Simulation Studies. The characteristics of the proposed model for dual-porosity/dual permeability reservoirs will be discussed. Two types of gases (lean and rich) were used for validating the presented model.

2.1.1. Model Setup. The compositional simulator (Elipse300) was utilized to set up a single vertical model in radial coordinates. The thickness of the synthetic multilayer model proposed for the dual-porosity/dual-permeability reservoir is $100 \mathrm{ft}$. For attaining a better resolution near the wellbore to detect condensate behavior, the gird blocks were adjusted, so that their numbers increased logarithmically toward the well. The reservoir simulation input, initial reservoir saturations, rock properties, and rate schedules are presented in Tables $1-4$, respectively.

2.1.2. PVT Modeling. The reservoir fluid behavior is an essential part of reservoir simulation. The PVTi package is utilized to simulate the reservoir fluid properties. The results of all PVT experiments are matched simultaneously to determine a representative equation of state (EOS) for the reservoir fluid. 3-parameter Peng-Robinson (PR3) with lumped 8 and 13 components is selected as EOS input into the simulator in lean and rich gas, respectively. Tables 5 and 6 show the composition of lean and rich gas, and Table 7 summarizes detailed results of PVT matching.

2.1.3. Relative Permeability. The feed relative permeability data in the simulator were taken from laboratory core analysis. Since the relative permeability curve in gas condensate reservoirs depends mainly on velocity and IFT, Eclipse-300 interpolates the objective curve between a base and a miscible curve. The base curve is measured when IFT is at the highest level, and velocity is at the lowest possible level. The miscible curve accounts for inertial effects. The interpolation is weighted by capillary number dependent functions.

2.2. Model Validation. The output of the well test model was used to validate the accuracy of the proposed numerical model. To compare the results of real field (input data of simulator) and simulations, the buildup test was conducted. Tables 8 and 9 represent the comparison results above the dew point pressure.

2.2.1. Simulation Results. The proposed models (lean and rich gas condensate) are representative of dual-porosity/ dual-permeability NFR, and the main objective is the 


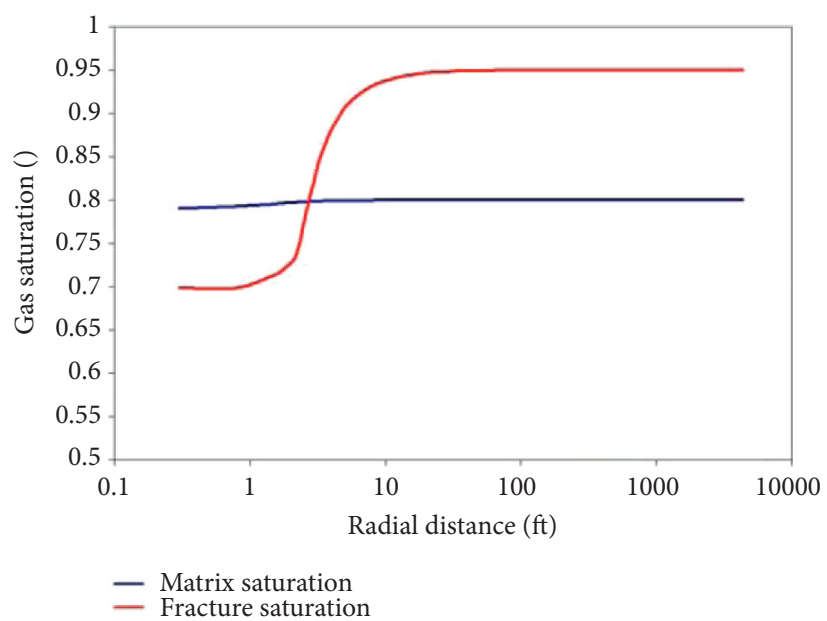

FIGURE 8: Gas saturation profile for idealizations of dual-porosity/dual-permeability gas-condensate reservoirs [21].

TABle 1: Reservoir simulation input data for the reservoir model.

\begin{tabular}{lc}
\hline \multicolumn{1}{c}{ Grid information } \\
\hline Number of cells in r-direction, $I_{\max }$ & 52 \\
Number of cells (layers) in $z$-direction, $K_{\max }$ & 15 \\
Reservoir radius $\left(r_{e}\right),(\mathrm{ft})$ & 6000 \\
\hline \multicolumn{1}{c}{ Well information } \\
\hline Wellbore radius $\left(r_{w}\right),(\mathrm{ft})$ & 0.25 \\
Wellbore storage coefficient $\left(C_{w}\right)[\mathrm{RB} / \mathrm{psi}]$ & 0 \\
Roughness & 0 \\
Perforated nodes & $1-15$ \\
\hline
\end{tabular}

TABLE 2: Initial saturation for the reservoir model.

\begin{tabular}{llll}
\hline & \multicolumn{2}{c}{ Initial saturation } & \\
& Matrix & & \multicolumn{2}{c}{ Fracture } \\
\hline$S_{w i}$ & 0.36 & $S_{w i}$ & 0.00 \\
$S_{o i}$ & 0.00 & $S_{o i}$ & 0.00 \\
$S_{g i}$ & 0.63 & $S_{g i}$ & 1.00 \\
\hline
\end{tabular}

investigation of condensate blockage. Simulation scenarios and their characteristics are presented in Table 10.

In addition, the log-log plot of buildup data for lean and rich gas reservoir model at pressures above and below dew point is shown in Figures 9 and 10.

\section{Discussion}

As can be seen in both Figures 9 and 10, the effect of condensate accumulation is superimposed on dual-porosity/ dual-permeability flow behavior. The observed fluid flow behavior can be categorized into early transition and late time zones.

3.1. Early Time Behavior. Derivative curves indicate that, below the dew point, reduced mobility region is formed near the wellbore. This behavior occurs after an upward shift in the early time derivative stabilization. Although more liquid saturation is formed in the case of the rich gas condensate system compared to the lean one, there is no sharp difference
TABLE 3: Rock properties for the reservoir model.

\begin{tabular}{lccc}
\hline & \multicolumn{2}{c}{ Rock properties } & \\
& Matrix & \multicolumn{2}{c}{ Fracture } \\
\hline$k^{[m d]}$ & 1.2 & $k^{[m d]}$ & 9000 \\
$\varphi$ & 0.11 & $\varphi$ & 1 \\
$C_{f}^{[p s i-1]}$ & $4.25 \mathrm{E}-06$ & $C_{f}[p s i-1]$ & $1 \mathrm{E}-4$ \\
\hline
\end{tabular}

TABLE 4: Rate schedule for the modified isochronal test.

\begin{tabular}{lc}
\hline Elapse time $(\mathrm{hr})$ & Gas rate ( Mscf/day) \\
\hline 600 & 8000 \\
9.6 & 0 \\
1200 & 10000 \\
9.6 & 0 \\
2400 & 12000 \\
12 & 0 \\
\hline
\end{tabular}

in the upward shift between these two different gas systems. This phenomenon is observed because condensate is mainly developed in the high mobility of the fracture systems.

3.2. Transition Behavior. Fluid flow between the matrix and fractures in the reservoir starts at the transition zone. Any phenomenon that restricted this communication results in the expansion of this period. Interpretations of log-log curves reveal that the surface of matrix blocks can be damaged by condensate formation. This damage is interpolated by an additional interporosity skin factor. This particular skin factor causes a delay in fluid flow from the matrix blocks to the fractures. Since the rich gas is more prone to condensation with respect to the lean gas, the skin factor is higher in the rich gas system. Consequently, the reduction in the value of interlayer cross-flow coefficient $\lambda$ is more. This fact is illustrated in Figures 9 and 10, in which the derivative curve is shifted to the right in the transition period.

3.3. Late Time Behavior. As the bottom-hole pressure decreases, more condensate is formed and accumulated. If the entire reservoir pressure drops below the dew point, the 
TABLE 5: Composition of lean gas/condensate fluid.

\begin{tabular}{lcc}
\hline Number & Components & Mole fraction (\%) \\
\hline 1 & $\mathrm{PC1}\left(\mathrm{C}_{1}, \mathrm{~N}_{2}\right)$ & 86.065 \\
2 & $\mathrm{C}_{2}$ & 5.23 \\
3 & $\mathrm{PC} 2\left(\mathrm{C}_{3}, \mathrm{H}_{2} \mathrm{~S}\right)$ & 2.18 \\
4 & $\mathrm{CO}_{2}$ & 1.93 \\
5 & $\mathrm{PC3}\left(\mathrm{iC}_{4}, \mathrm{NC}_{4}, \mathrm{C}_{5}, \mathrm{iC}_{5}, \mathrm{NC}_{5}\right)$ & 1.75 \\
6 & $\mathrm{PC4}\left(\mathrm{C}_{6}, \mathrm{BEN}, \mathrm{C}_{7}, \mathrm{TOL}, \mathrm{C}_{8}, \mathrm{C}_{9}, \mathrm{C}_{10}, \mathrm{C}_{11}, \mathrm{C}_{12}\right)$ & 2.34 \\
7 & $\mathrm{PC} 5\left(\mathrm{C}_{13}\right.$ to $\left.\mathrm{C}_{19}\right)$ & 0.42 \\
8 & $\mathrm{PC6}\left(\mathrm{C}_{20}\right.$ to $\mathrm{C}_{35}$ and $\left.\mathrm{C}_{36+}\right)$ & 0.085 \\
\hline
\end{tabular}

TABLE 6: Composition of rich gas/condensate fluid.

\begin{tabular}{lcc}
\hline Number & Components & Mole fraction (\%) \\
\hline 1 & $\mathrm{~N}_{2}$ & 3.48 \\
2 & $\mathrm{CO}_{2}$ & 7.60 \\
3 & $\mathrm{C}_{1}$ & 85.43 \\
4 & $\mathrm{C}_{2}$ & 3.05 \\
5 & $\mathrm{C}_{3}$ & 3.61 \\
6 & $\mathrm{iC}_{4}$ & 0.62 \\
7 & $\mathrm{NC}_{4}$ & 1.08 \\
8 & $\mathrm{iC}_{5}$ & 0.31 \\
9 & $\mathrm{NC}_{5}$ & 0.41 \\
10 & $\mathrm{C}_{6}$ & 0.47 \\
11 & $\mathrm{PC} 1\left(\mathrm{C}_{7}\right.$ to $\left.\mathrm{C}_{12}\right)$ & 3.07 \\
12 & $\mathrm{PC} 2\left(\mathrm{C}_{13}\right.$ to $\left.\mathrm{C}_{22}\right)$ & 1.02 \\
13 & $\mathrm{PC} 3\left(\mathrm{C}_{23+}\right)$ & .85 \\
\hline
\end{tabular}

TABLE 7: Comparison between observed and calculated PVT data.

\begin{tabular}{lccc}
\hline & $\begin{array}{c}\text { Observed dew point pressure } \\
\text { (psia) }\end{array}$ & $\begin{array}{c}\text { Calculated dew point pressure } \\
\text { (psia) }\end{array}$ & $\begin{array}{c}\text { Maximum liquid dropout in the CVD experiment (\%) Observed } \\
\text { and calculated) }\end{array}$ \\
\hline $\begin{array}{l}\text { Lean } \\
\text { gas }\end{array}$ & 4898 & 4891.37 & 4 \\
$\begin{array}{l}\text { Rich } \\
\text { gas }\end{array}$ & 3250 & 3235 & 1.9 \\
\hline
\end{tabular}

TABle 8: Buildup test analysis for the lean gas reservoir model above the dew point pressure.

\begin{tabular}{|c|c|c|}
\hline & Input data & Log-log analysis \\
\hline$P_{i}[P$ sia $]$ & 6000 & 5984 \\
\hline$k h[m d-f t]$ & 480 & 452 \\
\hline$k_{r e f f}[m d]$ & 4.61 & 4.34 \\
\hline
\end{tabular}

TABLE 9: Buildup test analysis for the rich gas reservoir model above the dew point pressure.

\begin{tabular}{lcc}
\hline & Input data & Log-log analysis \\
\hline$P_{i}[P$ sia $]$ & 4000 & 3994 \\
$k h[m d-f t]$ & 480 & 463 \\
$k_{r e f f}[m d]$ & 4.61 & 4.45 \\
\hline
\end{tabular}

TABLE 10: Summary of simulation models run in this work.

\begin{tabular}{lcr}
\hline & Above dew point & Below dew point \\
\hline Lean gas & $P_{i}=6000$ & $P_{i}=4500$ \\
Rich gas & $P_{i}=4000$ & $P_{i}=3300$ \\
\hline
\end{tabular}




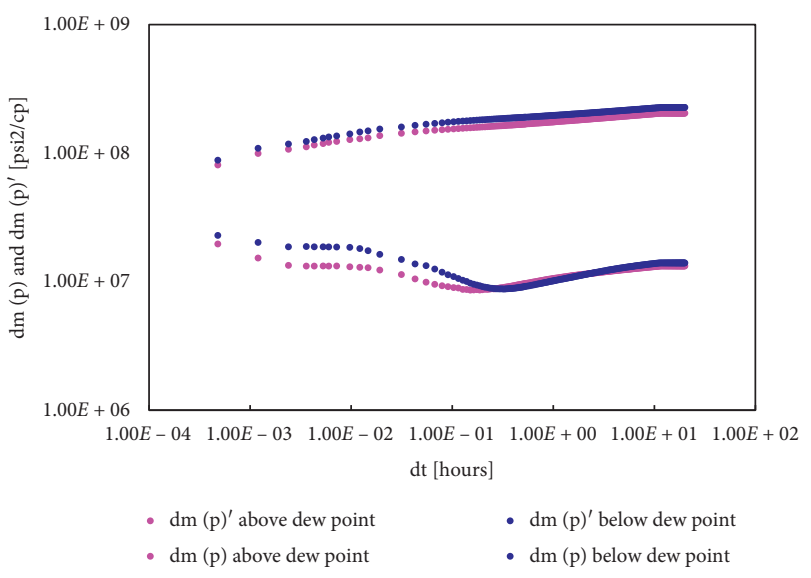

Figure 9: Log-log plot of buildup test results for the lean gas reservoir model.

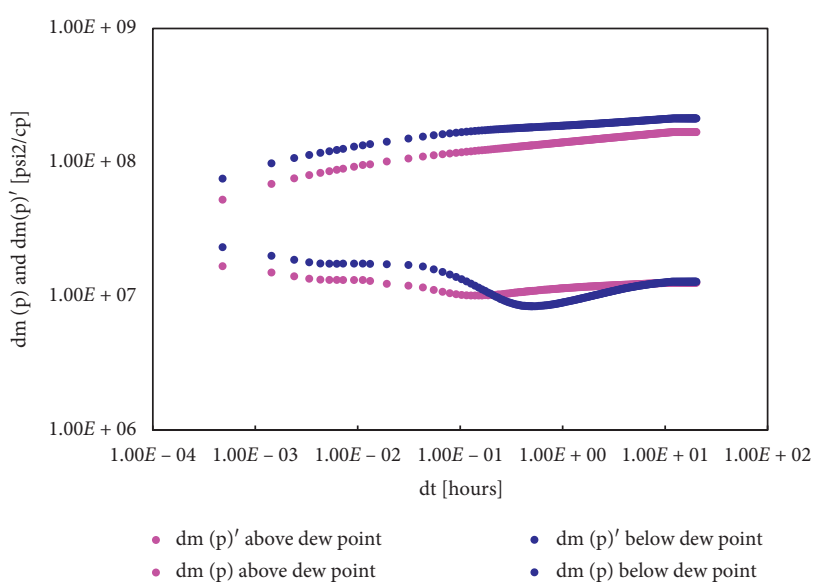

Figure 10: Log-log plot of buildup test results for the rich gas reservoir model.

composite behavior can appear at the late times. This situation happens more in the lean gas system, in which condensate can be formed in the entire reservoir. On the contrary, in the rich gas system, the falling of reservoir pressure below the dew point is less probable; thus, the probability of condensate formation in the entire reservoir, especially in far regions from the wellbore, is less. In this situation, late time stabilization is the same for both below and above dew point cases (Figure 10). Similar to the early times periods, liquid condensation causes a reduction in $k_{r g}$, which is characterized with an upward shift in the late time derivative stabilization (Figure 9).

\section{Conclusion}

The outcomes of the proposed simulator for detecting the condensate formation in lean and rich gas reservoirs lead to the following conclusion:

(1) During the well test analysis of gas condensate naturally fractured reservoirs, condensate creation adds more complexity to the analysis.
(2) Since external edges of the matrix blocks will be the first to host condensate in the system, condensation deposition creates an impediment layer at surface of the matrix blocks, which results in delaying matrix feeding to fractures. This phenomenon shifts pressure derivative curve to the right and causes deeper transition period.

(3) The richer gas is more prone to condensation. When the pressure drops below the dew point, the pressure derivative curves in rich gas system encounter a more shift to the right, and the trough becomes more prominent as compared to the lean one.

(4) Applying conventional analytical techniques for analyzing the pressure behavior in gas condensate NFRs suffered condensate banking issue, leading to unreliable results. In order to address this issue, the numerical simulation for more accurate results should be used.

\section{Nomenclatures}

$c_{t}: \quad$ Total compressibility $\left(\mathrm{psi}^{-1}\right)$

$c_{t}: \quad$ Total compressibility $\left(\mathrm{psi}^{-1}\right)$

$h_{1}, h_{2}$ : Thickness of the layer $(\mathrm{ft})$

$k_{1}, k_{2}$ : Permeability of the layer $(\mathrm{mD})$

$k_{z 1}$, Vertical permeability of the layer $(\mathrm{mD})$

$k_{z 2}$ :

$k_{m}: \quad$ Matrix permeability $(\mathrm{mD})$

$k_{f}: \quad$ Fracture permeability $(\mathrm{mD})$

$k_{r g}: \quad$ Gas relative permeability

${ }_{L}^{m}: \quad$ Characteristic fracture spacing, $\mathrm{ft}$

$n$ : $\quad$ Number of orthogonal sets of parallel fractures (1, 2 or 3)

$\varphi: \quad$ Porosity

$P: \quad$ Pressure (psi)

${ }_{P}^{i}: \quad$ Initial pressure $(\mathrm{psi})$

$r_{w}$ : Wellbore radius $(\mathrm{ft})$

Subscripts

$f$ : Fracture

i: Initial

$m$ : Matrix.

\section{Data Availability}

The data used to support the findings of this study are included within the article.

\section{Conflicts of Interest}

The authors declare that they have no conflicts of interest.

\section{References}

[1] M. Presho, S. Wo, and V. Ginting, "Calibrated dual porosity, dual permeability modeling of fractured reservoirs," Journal of Petroleum Science and Engineering, vol. 77, 2011.

[2] P. Ø. Andersen, "A simplified modelling approach for petroleum recovery by spontaneous imbibition in naturally fractured reservoirs," Journal of Natural Gas Science and Engineering, vol. 63, 2019. 
[3] G. H. Spence, G. D. Couples, T. G. Bevan et al., "Advances in the study of naturally fractured hydrocarbon reservoirs: a broad integrated interdisciplinary applied topic," Geological Society Special Publication, vol. 374, 2014.

[4] P. Lemonnier and B. Bourbiaux, "Simulation of naturally fractured reservoirs. State of the art: Part 2 - matrix-fracture transfers and typical features of numerical studies," Oil \& Gas Science and Technology - Revue d'IFP Energies nouvelles, vol. 65, 2010.

[5] P. Lemonnier and B. Bourbiaue, "Simulation of naturally fractured reservoirs. State of the Art: Part 1 - physical mechanisms and simulator formulation," Oil \& Gas Science and Technology, vol. 65, 2010.

[6] H. Esfandyari, A. Moghani Rahimi, F. Esmaeilzadeh et al., "Amphoteric and cationic surfactants for enhancing oil recovery from carbonate oil reservoirs," Journal of Molecular Liquids, vol. 322, 2020.

[7] M. Yazdi, "Ignorance-aware safety and reliability analysis: a heuristic approach," Quality and Reliability Engineering International, vol. 36, 2020.

[8] S. Kabir, T. K. Geok, M. Kumar, M. Yazdi, and F. Hossain, "A method for temporal fault tree analysis using intuitionistic fuzzy set and expert elicitation," IEEE Access, vol. 8, pp. 980-996, 2020.

[9] A. Firoozabadi, "Recovery mechanisms in fractured reservoirs and field performance," Journal of Petroleum Technology and Alternative Fuels, vol. 39, 2000.

[10] J. M. Babadimas, "Modelling trapped gas expansion in waterdrive reservoirs," in Proceedings of the SPE/IATMI Asia Pacific Oil \& Gas Conference and Exhibition, Jakarta, Indonesia, October 2017.

[11] J. R. Gilman and H. Kazemi, "Improvements IN simulation OF naturally fractured reservoirs," Society of Petroleum Engineers Journal, vol. 23, 1983.

[12] J. Yang, C. Li, S. Geng, S. He, and K. Li, "Microscopic flow mechanism of water invasion in ideal fracture models," Energy Sources, Part A Recover, vol. 28, 2020.

[13] D. A. Davidson and D. M. Snowdon, "Beaver river middle devonian carbonate: performance review OF a high-relief, fractured gas reservoir with water influx," Journal of Petroleum Technology, vol. 30, 1978.

[14] G. Wei, G. Chen, S. Du, L. Zhang, and W. Yang, "Petroleum systems of the oldest gas field in China: neoproterozoic gas pools in the Weiyuan gas field, Sichuan Basin," Marine and Petroleum Geology, vol. 25, 2008.

[15] R. Aguilera, J. J. Conti, and E. A. Lagrenade, "Reducing gasproduction decline through dewatering: a case history from the naturally fractured Aguarague field, Salta Argentina," SPE Reservoir Evaluation \& Engineering, vol. 6, 2003.

[16] J. E. Warren and P. J. Root, "The behavior of naturally fractured reservoirs," Society of Petroleum Engineers Journal, vol. 3, 1963.

[17] E. W. Moore, C. W. Crowe, and A. R. Hendrickson, "Formation, effect and prevention of asphaltene sludges during stimulation treatments," Journal of Petroleum Technology, vol. 17, 1965.

[18] G. I. Barenblatt, I. P. Zheltov, and I. N. Kochina, "Basic concepts in the theory of seepage of homogeneous liquids in fissured rocks [strata]," Journal of Applied Mathematics and Mechanics, vol. 24, 1960.

[19] E. Hamid, A. Moghani, F. Esmaeilzadeh, and A. Davarpanah, "A laboratory approach to measure carbonate rocks' adsorption density by surfactant and polymer," Hindawi
Mathematical Problems in Engineering, vol. 2021, Article ID 5539245, 7 pages, 2021.

[20] M. Abbasi, M. Madani, M. Sharifi, and A. Kazemi, "Fluid flow in fractured reservoirs: exact analytical solution for transient dual porosity model with variable rock matrix block size," Journal of Petroleum Science and Engineering, vol. 164, 2018.

[21] D. Bourdet, Well Test Analysis: The Use of Advanced Interpretation Models, 2002.

[22] F. Kuchuk and D. Biryukov, "Pressure-transient behavior of continuously and discretely fractured reservoirs," SPE Reservoir Evaluation \& Engineering, vol. 17, 2014.

[23] Z. X. Chen, "Transient flow of slightly compressible fluids through double porosity double permeability systems a state of the art review," Transport in Porous Media, vol. 4, no. 2, pp. 147-184, 1989.

[24] M. Yazdi, "Introducing a heuristic approach to enhance the reliability of system safety assessment," Quality and Reliability Engineering International, vol. 35, 2019.

[25] M. Yazdi, "Footprint of knowledge acquisition improvement in failure diagnosis analysis," Quality and Reliability Engineering International, vol. 35, 2019.

[26] D. O. Egya, S. Geiger, P. W. M. Corbett et al., "Analysing the limitations of the dual-porosity response during well tests in naturally fractured reservoirs," Petroleum Geoscience, vol. 25, 2019.

[27] Y. Wan, Y. Liu, W. Ouyang, G. Han, and W. Liu, "Numerical investigation of dual-porosity model with transient transfer function based on discrete-fracture model," Applied Mathematics and Mechanics (English Edition), vol. 37, 2016.

[28] A. Taymourtash and B. S. Sola, "Investigation of applicability of dual-porosity model for polymer flooding simulation," Journal of Porous Media, vol. 21, 2018.

[29] K. L. Morton, F. J. Kuchuk, and A. J. Fitzpatrick, "Active and interference well pressure transient data interpretation in naturally fractured reservoirs," in Proceedings of the 77th EAGE Conference and Exhibition 2015, Madrid, Spain, June 2015.

[30] A. C. Gringarten, A. Al-Lamki, S. Daungkaew, R. Mott, and T. M. Whittle, "Well test analysis in gas-condensate reservoirs," in Proceedings of the SPE Annual Technical Conference and Exhibition, Dallas, Texas, U.S.A, October 2000.

[31] A. Afanasyev, "Fluid displacement in a dual-permeability medium with local capillary equilibrium," Transport in Porous Media, vol. 135, 2020.

[32] J. Lu, J. Qu, and M. M. Rahman, "A new dual-permeability model for naturally fractured reservoirs," Special Topics \& Reviews in Porous Media, vol. 10, 2020.

[33] J. P. Aguilar-López, T. Bogaard, and H. H. Gerke, "Dualpermeability model improvements for representation of preferential flow in fractured clays," Water Resources Research, vol. 56, 2020.

[34] A. C. Hill and G. W. Thomas, New approach for simulating complex fractured reservoirs, 1985.

[35] F. T. Blaskovich, G. M. Cain, S. Fernand, D. Waldren, and S. J. Webb, "Multicomponent isothermal system for efficient reservoir simulation," 1983.

[36] C.A. Pereira Tavares, H. Kazemi, and E. Ozkan, "Combined effect of non-Darcy flow and formation damage on gas-well performance of dual-porosity and dual-permeability reservoirs," Procedia Manufacturing, vol. 48, 2006.

[37] R. Dastoorian and L. Wells, Gauge capability studies for highdensity data: SPC Phase 0, 2020.

[38] M. Safari-Beidokhti and A. Hashemi, "Condensate blockage effects in well test analysis of dual-porosity/dual-permeability, 
naturally fractured gas condensate reservoirs: a simulation approach," Journal of Petroleum Exploration and Production Technology, vol. 6, 2016.

[39] A. Al-Muftah, Well test simulation for dual porosity-dual permeability using orthogonal collocation, 2017.

[40] A. A. Alramadhan, R. J. Guerrero, A. M. Alzahrani, and B. A. Al Awami, "Numerical approach in analyzing pressure transient responses in dual-porosity dual-permeability DPDP reservoirs," in Proceedings of the SPE Middle East Oil and Gas Show and Conference, Abu Dhabi, UAE, March 2019.

[41] V. de Souza Rios, D. J. Schiozer, L. O. S. Dos Santos, and A. Skauge, "Improving coarse-scale simulation models with a dual-porosity dual-permeability upscaling technique and a near-well approach," Journal of Petroleum Science and Engineering, vol. 198, 2021.

[42] K. Uleberg and J. Kleppe, "Dual Porosity, Dual Permeability Formulation for Fractured Reservoir Simulation," Norwegian University of Science and Technology (NTNU), Stavanger, Norway, 1996.

[43] N. A. Golilarz, H. Gao, S. Pirasteh, M. Yazdi, J. Zhou, and $\mathrm{Y}$. Fu, "Satellite multispectral and hyperspectral image denoising with enhanced adaptive generalized Gaussian distribution threshold in the wavelet domain," Remote Sensing, vol. 13, 2021.

[44] M. R. Maleki, F. Rashidi, H. Mahani, and E. Khamehchi, “A simulation study of the enhancement of condensate recovery from one of the Iranian naturally fractured condensate reservoirs," Journal of Petroleum Science and Engineering, vol. 92, pp. 158-166, 2012.

[45] H. M. Uba, Y. Chiffoleau, T. Pham, V. Divry, A. Kaabi, and J. Thuwaini, "Application of a hybrid dual-porosity/dualpermeability representation of large-scale fractures to the simulation of a giant carbonate reservoir," in Proceedings of the SPE Middle East Oil and Gas Show and Conference, Manama, Bahrain, March 2007.

[46] H. Uematsu, G. Auxiette, S. Bellah, V. Virlan, and T. Stojic, "New approach using dual porosity dual permeability and dissolved pore network to simulation modeling for fractured carbonate reservoir in Abu Dhabi," in Proceedings of the Abu Dhabi International Petroleum Exhibition \& Conference, Abu Dhabi, UAE, November 2017.

[47] K. Sepehrnoori, Y. Xu, and W. Yu, "Numerical approaches for modeling complex fractures," Developments in Petroleum Science, pp. 31-42, 2020.

[48] F. Torres, M. Xavier, J. Ailin et al., Comparison of Dual Porosity Dual Permeability with Embedded Discrete Fracture Model for Simulation Fluid Flow in Naturally Fractured Reservoirs, 2020.

[49] L. J. Wells, R. Dastoorian, and J. A. Camelio, “A novel NURBS surface approach to statistically monitor manufacturing processes with point cloud data," Journal of Intelligent Manufacturing, vol. 32, no. 2, pp. 329-345, 2021.

[50] S. Granet, P. Fabrie, P. Lemonnier, and M. Quintard, “A twophase flow simulation of a fractured reservoir using a new fissure element method," Journal of Petroleum Science and Engineering, vol. 32, 2001.

[51] S. Kumar, A. Rey, G. Dufour, and B. Ogunyomi, "Understanding fluid flow behavior in fractured reservoir using dual porosity dual permeability and discretized fracture model," in Proceedings of the SPE Annual Technical Conference and Exhibition, Calgary, Canada, October 2019.

[52] E. M. Mansour and M. El Aily, "Hydrocarbon simulation behavior of wet natural gas reservoirs, Egypt," Journal of Chemistry, vol. 64, 2021.
[53] R. Jadidi, B. Sedaee, S. Gerami, and A. Nakhaee, "Development of production data analysis models for multi-well gas condensate reservoirs," Journal of Petroleum Science and Engineering, vol. 202, 2021.

[54] Y. Yang, H. Wang, Z. Lun, and W. Hu, "A new method to calculate the in-situ compositions of gas condensate reservoirs," Energy Sources, Part A Recover, 2020.

[55] S. H. Yousefi, A. Eslamian, and F. Rashidi, "Investigation of well test behavior in gas condensate reservoir using singlephase pseudo-pressure function," Korean Journal of Chemical Engineering, vol. 31, 2014.

[56] L. Fan, B. W. Harris, A. Jamaluddin et al., "Understanding gas-condensate reservoirs," Corrosion in the Oil Industry, vol. 17, 2005.

[57] M. Bozorgzadeh and A. C. Gringarten, "Condensate-bank characterization from well-test data and fluid PVT properties," SPE Reservoir Evaluation \& Engineering, vol. 9, 2006.

[58] B. Onoabhagbe, P. Russell, J. Ugwu, and S. Rezaei Gomari, "Application of phase change tracking approach in predicting condensate blockage in tight, low, and high permeability reservoirs," Energies, vol. 13, 2020.

[59] $\varnothing$. Fevang and C. H. Whitson, "Modeling gas-condensate well deliverability," SPE Reservoir Evaluation \& Engineering, vol. 11, 1996.

[60] M. Yazdi, F. Khan, and R. Abbassi, "A dynamic model for microbiologically influenced corrosion (MIC) integrity management of subsea pipelines," Journal of Hazardous Materials, vol. 127, 2021.

[61] R. J. Wheaton and H. R. Zhang, "Condensate banking dynamics in gas condensate fields: compositional changes and condensate accumulation around production wells," in Proceedings of the SPE Annual Technical Conference and Exhibition, Dallas, TX, U.S.A, October 2000.

[62] R. Mott, "Engineering calculations of gas-condensate-well productivity," SPE Reservoir Evaluation \& Engineering, vol. 6, 2003.

[63] S. Bapat and N. Akhter, Mathematical Model for Predicting the Reservoir Performance of Gas Condensate in Multiphase Flow Systems, 2020.

[64] K. Davani, S. Kord, O. Mohammadzadeh, and J. Moghadasi, "Numerical simulation and three-phase pressure transient analysis considering capillary number effect - case study of a gas condensate reservoir," International Journal of Oil, Gas and Coal Technology, vol. 25, 2020.

[65] D. H. Pham, S. K. Hoang, V. X. Trinh, and T. V. Tran, Condensate Banking Characterization and Quantification of Improvement from Different Mitigations Using Pressure Transient Analysis: A Case Study in Hai Thach Field Offshore Vietnam, 2020.

[66] M. P. P. C. Santos and M. S. Carvalho, "Pore network model for retrograde gas flow in porous media," Journal of Petroleum Science and Engineering, vol. 185, 2020.

[67] N. Salmani, R. Fatehi, and R. Azin, "On the liquid condensate vertical migration near the production wells of gas-condensate reservoirs," Engineering Science and Technology an International Journal, vol. 23, 2020.

[68] A. Rahimzadeh, M. Bazargan, R. Darvishi, and A. H. Mohammadi, "Condensate blockage study in gas condensate reservoir," Journal of Natural Gas Science and Engineering, vol. 33, 2016.

[69] M. Muskat, "Physical principles of oil production," The Journal of Geology, vol. 59, no. 5, pp. 513-515, 1949. 
[70] D. D. Fussell, "Single-well performance predictions for gas condensate reservoirs," Journal of Petroleum Technology, vol. 25, 1973.

[71] J. R. Jones and R. Raghavan, "Interpretation of flowing well response in gas-condensate wells," SPE (Society of Petroleum Engineers) Format Evaluation, vol. 3, 1988.

[72] G. Penuela and F. Civan, Gas-Condensate Well Test Analysis with and without Relative Permeability Curves, 2000. 